\title{
When will I ever use that? Giving students opportunity to see the direct application of modelling techniques in the real world.
}

\author{
Ros Porter, Dept. of Engineering and Mathematics, Sheffield Hallam University, Sheffield, UK. \\ Email: r.porter@shu.ac.uk \\ Hannah Bartholomew, Dept. of Engineering and Mathematics, Sheffield Hallam University, \\ Sheffield, UK. Email: h.bartholomew@shu.ac.uk
}

\begin{abstract}
Mathematical modelling is unfamiliar to many young mathematicians and can be a source of anxiety for many. Although many first year mathematics undergraduates will have used mathematical models throughout GCSE and A Level most are unaware of this. Very few understand what a mathematical model is, fewer still the concept of building a model. In our experience students are reluctant to try and build their own models and fail to see the value of modelling skills in the real world. We invited 3 speakers to attend a first year modelling lecture to talk about the models they use in their jobs with the intention that this would help students see that modelling skills and analytical thought processes are valuable tools for a maths graduate. The speakers had different employment backgrounds being from banking, research (chemistry) and transport engineering. Each spoke for approximately 10 mins. giving an outline of their field. The lecture was followed by tutorials in which students were asked to reflect on what the speakers had said and how this related to their own learning. Two of the speakers also attended the tutorials and were able to have more informal conversations with the students.
\end{abstract}

Keywords: Modelling, skills, employability, reflection.

\section{Introduction}

Sheffield Hallam University (SHU) has a strong reputation for embedding employability within its Maths degree (Robinson, Challis and Thomlinson, 2010; Pegg et al., 2012). One of the modules that contributes to the development of graduate skills is Modelling 1, the first year modelling 20 credit core module. The first year cohort is approximately 100 students from a variety of backgrounds. Most students are within a year or two of completing A levels, some are direct entry from the Extended degree (Prep year) in Engineering and Maths and a few are mature students. In 20142015 the students on Modelling 1 received a 1 hour lecture to the whole cohort followed by a 1 hour tutorial in groups of approximately 25 students.

The module aims to develop students' modelling skills by giving them opportunity to work on different problems. The problems come from diverse areas such as engineering, population growth, management science and diffusion.

\subsection{Project Outline}

The project funded by an internal University Teaching Enhancement Fund invited 3 external speakers to one lecture. Each speaker was asked to present for approximately 10 minutes allowing 5 minutes for questions. The speakers were briefed to talk about how they used Modelling in their jobs and how they dealt with uncertainty in real situations. The speakers were from banking, transport engineering and chemistry research. Two of the speakers were SHU BSc Maths alumni.

The lecture was followed by lunch and then 2 hours of tutorials (with 2 tutorial groups in each hour). During the tutorials students were asked to consider questions in groups with their responses 
recorded through the freely available Socrative software app. Two of the speakers were able to stay to the tutorials and talk more informally with the students in small groups.

The project was evaluated through an informal discussion with the speakers over lunch, the results of the Socrative quiz, student feedback in their online progress files and personal reflection.

\subsection{Rationale}

Hibberd (2002) and Savage and Grove (2015) discuss the importance of key skills that can be developed through the modelling process although Hibberd (2002) acknowledges that the skills themselves are not easy to teach but can be enhanced by learning activities. We feel that alongside these activities it is also necessary to encourage reflection to enable students to see the skills they are developing.

The Mathematics, Statistics and Operational Research benchmark statement (QAA, 2015) outlines the importance of Modelling in its own right. In addition it is expected that 'Graduates have an understanding of the importance of assumptions and an awareness of where they are used and of possible consequences of their violation.' (Section 3.12, p.15, QAA, 2015)

The vast majority of students beginning the Maths degree at SHU have little or no previous experience of mathematical modelling and do not know what it entails. This echoes the findings of Grove (2012). The students at SHU are asked to reflect on their progress in each module every week in an online progress file. The form is accessed through the SHUMaths website. Students can see and edit their own comments but do not have access to other students' entries. All staff teaching the BSc Mathematics modules can view and respond to comments left by students. The progress file is marked fortnightly throughout the first year of the degree. Marks for engagement contribute a small percentage of marks towards another first year module. Comments from the first week of Modelling 1 include, "I have never done maths like it before", "Not clearly understood what modelling is exactly" and "I have an understanding of basic modelling, am yet to understand the concept behind $i t$. Some students are even afraid of the module commenting "this was the one that I was scared off'.

For many the lack of certainty is a concern; with comments such as "was slightly confusing, prefer things with one fixed answer" and "I found modelling difficult because it's like nothing l've ever done before". Other students are more positive, "This helped me see maths in a different way," although some still have misgivings; "I like the idea of solving real world problems, however knowing that there is several answers to a particular question, or not fully understanding what the question is may frustrate me", "modelling isn't my idea of maths as I like the fact with maths there is always an answer but it will help in the long run to see the bigger picture".

We wanted students to leave behind their fears and insecurities and help them to appreciate the importance of modelling skills. Dealing with uncertainty is a difficult thing to do, especially when you are so used to there being just one correct answer. We want our students to know that there are ways to deal with it and by solving one modelling problem you will develop skills to help you solve another one even though the mathematical techniques may be different. Nyman and Berry (2002) discuss developing a Modelling course with these generic skills in mind and acknowledge that "to the employer of our graduates these skills are often more important than the actual mathematics they have learnt".

Inglis, Croft and Matthews (2012) found that "applying mathematics to the real world" was the skill that most students felt they would have liked to have developed but were not given the opportunity to do so. The inclusion of 3 very different examples from industry should allow students to see that they are being given the opportunity here at Sheffield Hallam and are building up a set of transferable 
skills that can be applied in different contexts. These skills are important and will enhance their employability.

We also wanted to address the students discomfort with there not being 'one fixed answer' by asking our speakers to show how they address this issue in real life models.

\section{In Practice}

We began our search for speakers by initially putting out a call through the Linkedln group of SHUMaths Alumni and asking all of our final year students who had been on placement if they would be willing to talk about what they did on placement. This method yielded two speakers from the Alumni group. The third speaker was a personal contact.

The experience of the speakers varied; both in the amount of time working in their field and in giving presentations.

Overall the sessions were successful. The speakers felt the talks had gone well and we received much positive feedback from the students. Our own reflections were that it had gone well and that we would like to repeat something similar next year. However, there were areas we would like to improve next time.

The speakers were all positive about the lecture session and had enjoyed the experience. However, the two that attended the tutorial sessions felt that this was an easier platform in which to convey what their job entailed. Perhaps this was due to students feeling more comfortable to ask questions in small groups but also possibly due to the fact they had time in the lunch break in which to reflect on what they seen and to think of questions.

As the main purpose of the session was to improve students' perceptions of the importance of modelling we also wanted to find out what they got from the session. We received feedback from students primarily in two forms; the responses to the Socrative quiz completed in class and from their progress files completed individually in their own time up to 14 days after the event. It is interesting to note that the emphasis of the feedback varies depending on the form it took.

During the tutorial sessions students were encouraged to chat in small groups about the speakers and what they gained from it. There were given specific questions to answer which guided the discussions. After a short while discussing each question the group submitted their answers via the Socrative app. The class as a whole could see the comments of others and a summary was presented by the tutor with further comment from individual where appropriate. The Socrative quiz responses addressed both the modelling skills aspect of the session as well employability. When asked "What was the key benefit from today?" the majority of the comments involved seeing the 'real life' applications of modelling. Some focussed solely on improved knowledge of job opportunities but many covered both aspects. The feedback from the quiz questions was inevitably influenced not just by the wording of the questions themselves but also by us as their tutors as we directed the in-class discussions.

The main focus of the comments made in students' progress files was on employability issues, with comments such as "showed me some areas I could go into", "I hadn't even realised the job existed" and "made me reconsider what I wish to do in the future". Only one comment noting the sessions provided "some time to reflect on the module" could be interpreted as concerning the modelling skills.

Although students can write in their progress files at any time very few do so immediately after a session. As they are marked fortnightly it is not uncommon for students to make entries up to 14 
days after a taught session, although many students fill them in weekly or ad hoc throughout the week. The vast majority of the comments written in the progress files were at least a day or more after the lecture session. The fact that students are focussing on this after the event could be an indication that this is the main influence that the session had on them and that the application of modelling skills was less important.

We also asked the students for suggested improvements. Some suggested the use of examples more specific to models they were studying, some more variety and some fewer examples but more in depth.

Comments in both formats were overwhelmingly positive and included a "THANK You" (their emphasis). With many comments about how helpful and insightful it had been. Students commented that the tutorial sessions which gave the opportunity for 1-1 and small group discussions were particularly valuable. One student also mentioned the value in seeing where ex-students are now employed.

\section{Conclusion}

From our own perspective the lecture and tutorial session were well worth doing. The students found them to be of value and they evidently helped students see the wide variety of jobs in which modelling can be applied. It became apparent that the more informal discussions in the tutorials were felt to be of most benefit to several students.

However, we do not feel that all our aims have been met. Although asked to talk about uncertainty none of the speakers did so in the way we had hoped for. This suggests that in future the intended outcomes of the talks need to be more clearly communicated to the speakers.

The tutorial sessions were poorly attended; anecdotal evidence would suggest this was partly due to a coursework deadline and a lack of understanding in what we would be doing in these sessions. One student felt that the Socrative quiz could have been completed individually in their own time and didn't need a whole hour's tutorial devoted to it. This is an interesting comment and highlights that we need to spend more time and thought planning the reflective exercise and communicating this to students. Although students could reflect on their own we believe there is value to a shared reflective experience. This is something we need to make sure students understand in the future.

We have secured funding to run a similar session this year. We would like to build in more opportunity to have small group discussions. We will also devote time to planning a more structured discussion to enable students to highlight the transferable skills they are gaining and that the speakers are using.

We also hope to give more guidance to the speakers; making our aims clearer and asking for one example of developing a problem. We would like them within this to discuss the assumptions they make and how they deal with uncertainty.

In summary, it was a well-received way of giving students an authentic insight in to how and where models are applied in the real world. However, it was also a learning experience for us and we hope to deliver a more focussed session next year that meets more of our aims.

Perhaps we should give the last word to one of our students, although we cannot claim that the session with the speaker is the sole driver for the change of heart, we do think it helped. The student who began the year thinking "modelling isn't my idea of maths as I like the fact with maths there is always an answer" ended the year thinking "Modelling is one of my favourite modules as it used the pure maths to fix everyday problems and it's much more relatable." 


\section{References}

Grove, M., 2012. The Mathematical Transition: A Multi-Stage Problem? MSOR Connections 12 (1) pp. 15-18. Available at: https://www.heacademy.ac.uk/sites/default/files/msor.12.1.d.pdf [Accessed: 10 April 2016].

Hibberd, S., 2002. Mathematical modelling skills. In P. Kahn and J. Kyle, eds. Effective learning and teaching in Mathematics \& its applications. London: Kogan Page, pp.158-174.

Inglis, M., Croft, T., and Matthews, J., 2012. Graduates' Views on the Undergraduate Mathematics Curriculum. National HE STEM Programme and MSOR Network. Available at: http://www.mathcentre.ac.uk/resources/uploaded/gradviews.pdf [Accessed 10 April 2016].

Nyman,M. and Berry, J., 2002. Developing transferable skills in undergraduate mathematics students through mathematical modelling. Teaching Mathematics and Its Applications 21(1) pp.2945. Available at: http://teamat.oxfordjournals.org/content/21/1/29.abstract [Accessed: 10 April 2016].

Pegg, A., Waldock, J., Hendy-lsaac, S. and Lawton, R., 2012. Pedagogy for employability, HEA. [pdf] Available at:

https://www.heacademy.ac.uk/sites/default/files/pedagogy_for_employability_update_2012.pdf [Accessed 10 April 2016].

QAA, 2015. Subject Benchmark Statement: Mathematics, Statistics and Operational Research. [pdf] Available at: http://www.qaa.ac.uk/en/Publications/Documents/SBS-Mathematics-15.pdf [Accessed 10 April 2016].

Robinson, M, Challis, N and Thomlinson, M., eds., 2010. Maths at University: Reflections on experience, practice and provision, Birmingham: More Maths Grads.

Savage, M and Grove, M., 2015. Mathematical modelling and problem solving in real-world physical situations. In: Grove, M, Croft, T, Kyle, J and Lawson, D., eds., Transitions in Undergraduate Mathematics Education, Birmingham: University of Birmingham, pp.115-128. 